\title{
OS DOIS LADOS DO LIMITE DA CRÍTICA: POR QUE O NÚMENO FAZ PARTE DA ANALÍTICA?
}

\author{
Paulo Borges de Santana Júnior ${ }^{1}$ \\ Universidade de São Paulo (USP) \\ https://orcid.org/0000-0003-1240-9690 \\ E-mail:pauloemconstrucao@gmail.com
}

\section{RESUMO:}

A partir da preocupação sistemática com as divisões da CRP, abordamos o terceiro capítulo da Analítica dos Princípios, incluindo também suas teses sobre a transgressão da razão e sobre o "alargamento negativo". Nossa proposta é mostrar a especificidade do conceito de númeno frente às outras categorias do entendimento, sem perder de vista sua pertinência dentro da Analítica Transcendental. A peculiaridade desse conceito expressa de maneira privilegiada a relação da crítica com os limites do conhecimento, uma vez que númeno é uma representação posta fora da possibilidade da intuição, mas que é exposta por análise do conhecimento - e não por inferência, como seria o caso das ideias da razão. Propomos, portanto, lançar luz sobre os argumentos que, por um lado, limitam o conhecimento e, por outro, permitem ao pensamento uma via para prosseguir além da experiência. Desse modo, a posição do crítico, que na atividade de análise se desprende de interesses específicos em prol de uma investigação imparcial, consegue abarcar o dentro e o fora da delimitação conhecimento.

Palavra-chave: Analítica transcendental; Númeno; Limite; Crítica.

\section{THE TWO SIDES OF THE LIMIT OF CRITIQUE: WHY IS THE NOUMENON WITHIN THE TRANSCENDENTAL ANALYTIC?}

\begin{abstract}
:
Starting from our attention to the systematic divisions of the $K r V$, we address the chapter III of Analytic of principles and its theses on the transgression of reason and the negative expansion. Our proposal is to show the specificity of the concept of noumenon in relation to the other categories of understanding without neglecting its place within Transcendental Analytic. The peculiarity of this concept expresses in a privileged way the relation of critique to the limits of knowledge, since noumenon is a representation that is excluded from the possibility of intuition, but is included in the analysis of knowledge. We therefore intend to shed light on the arguments that, on the one hand, limit knowledge and, on the other hand, allow thought a way to go beyond experience. Thus, in the analysis activity that detaches itself from specific interests in favour of an impartial investigation, the critic's position can embrace the inside and the outside of the delimitation of knowledge.
\end{abstract}

KEYWORD: Transcendental Analytic ; Noumenon ; Limit ; Critique.

\footnotetext{
${ }^{1}$ Doutorando(a) em Filosofia na Universidade de São Paulo (USP), São Paulo - SP, Brasil. Bolsista do(a): Fundação de Amparo à Pesquisa do Estado de São Paulo ( FAPESP), São Paulo - SP, Brasil.
}

JÚNIOR, Paulo Borges de Santana. Os dois lados do limite da crítica: por que o númeno faz parte da Analítica?. Griot : Revista de Filosofia, Amargosa - BA, v.22 n.1, p.34-48, fevereiro, 2022. 


\section{Introdução}

O modo como o projeto crítico de Kant se relaciona com os limites por ele instituídos causa alegações de contradição como a famosa questão da coisa em si. Na célebre formulação de Jacobi seria impossível entrar na Crítica da razão pura sem a coisa em si e não se poderia permanecer na obra com a coisa em $\mathrm{si}^{2}$. Desse modo, o problema da coisa em si pode ser visto como um clássico exemplo desse limite que, por um lado, precisa ser posto fora do domínio do conhecimento, mas que, por outro, deve pertencer ao âmbito de uma investigação transcendental sobre a possibilidade do conhecimento. Essa duplicidade é fundamental para compreender como a crítica se amplia para além campo do conhecimento. Todavia, como abranger ao mesmo tempo os dois lados de um problema sem cair em imprecisão, sem criar tensões?

Sobre essa questão, Lebrun (2001) atribui uma força aporética à letra de Kant. Tal aporética visa reforçar a sinuosidade do texto no que tange a restrição das categorias do entendimento ao campo da intuição possível, restrição ora mais ora menos rigorosa no decorrer da obra. Na sinuosidade dos argumentos da Crítica da Razão Pura, de acordo com Lebrun, seria possível reconhecer uma exigência ou um desejo em direção a duas coisas opostas: a restrição do entendimento ao domínio teórico e a permissão à razão de ir além no domínio prático. Cabe indicar que Lebrun não indica diretamente uma aporia nas teses de Kant e reconhece que um esforço abstrativo poderia eliminar as suas ambiguidades. Em todo caso, haveria uma aporética, ou seja, uma força argumentativa ambivalente ora numa direção ora em outra. $O$ momento em que se expressaria com mais "didatismo" essa ambivalência seria o capítulo III da Analítica dos princípios, um capítulo que recolocaria o problema da coisa em si a partir do conceito de númeno. Assim, o problema da coisa em si, além de rondar a Estética transcendental e a receptividade do sujeito, retornaria depois da Dedução Transcendental e introduziria as primeiras bases para pensar uma causalidade distinta da fenomênica e fundamental para o domínio moral.

Para minimizar a característica aporética que envolveria a referência à coisa em si, Louzado (2005), por sua vez, toma justamente o caminho do esforço abstrativo de impedir que o juízo negativo sobre os númenos seja tomado por um juízo infinito. Em suma, a base dessa argumentação gira em torno da diferença entre juízos negativos e juízos infinitos, de modo que seja possível manter o juízo negativo de que o númeno não é algo sensível, sem inferir o juízo infinito de que o númeno seria algo não-sensível. Diferente do juízo infinito, o juízo negativo não carregaria nenhuma pretensão de conhecimento ${ }^{3}$. Assim, enfatizando a distinção que Kant faz entre sentido negativo e positivo de númeno, não haveria propriamente uma aporética ou um paradoxo que pressupusesse a necessidade de dois aspectos sobre o conhecimento, um próprio da crítica e outro próprio da ciência. $O$ argumento sinuoso de Kant sobre a coisa em si, dessa forma, apontaria para essa força abstrativa em direção a um objeto em geral ao qual poderia ser permitido negar a característica sensível e simultaneamente defender a impossibilidade de seu conhecimento. Por fim, para Louzado, negar a característica sensível da coisa em si não poderia ser considerado a pretensão de um tipo específico de conhecimento a respeito da coisa em si.

Se Louzado tenta resolver a força aporética que ronda a coisa em si pela distinção lógica entre juízos infinitos e juízos negativos, Hulshof enfatiza a função do conceito de númeno na Dialética Transcendental e seus apontamentos para o uso prático. Assim, o interesse num uso

\footnotetext{
2 Sobre a fecundidade desse problema que perpassa os pós-kantianos até Schopenhauer, cf. CACCIOLA, 1994.

3 Nessa formulação, Louzado busca dissolver o paradoxo expresso por Guyer, que afirma justamente o juízo (ou asserção) negativo como essa pretensão (claim) de conhecimento. Cf. GUYER, 1987, p. 335.
}

JÚNIOR, Paulo Borges de Santana. Os dois lados do limite da crítica: por que o númeno faz parte da Analítica?. Griot : Revista de Filosofia, Amargosa - BA, v.22 n.1, p.34-48, fevereiro, 2022. 
prático motivaria o discurso da crítica, depois de restringir o conhecimento teórico, a ir além da experiência. Segundo a intérprete, seria mais precisamente na terceira antinomia que encontraríamos uma justificação para pensar a causalidade não submetida à natureza ou ao fenomênico, ainda que esse pensar no nível de uma Dialética Transcendental permaneça uma suposição, ou seja, permaneça na modalidade problemática enquanto espera uma crítica da razão prática capaz de atribuir uma objetividade ao conceito de liberdade. Desse modo, a extensão da crítica para além do conhecimento significaria a introdução de um interesse prático da razão no fundamento da distinção entre númenos e fenômenos.

Tendo como ponto de partida em especial essas abordagens e seus diferentes interesses, elaboramos a tentativa de compreender essa ambivalência que envolve ou é posta pelo conceito de númeno em função do limite que a crítica impõe à razão especulativa, mas não a própria razão pura ${ }^{4}$. E em outro aspecto, propomos também a tentativa de compreender a ambivalência de um limite que, por um lado, se impõe ao conhecimento (teórico) e que, por outro, permite, legitima e (até) exige que o pensamento em geral o ultrapasse de algum modo. Porém, mais do que entender o númeno pelo conceito de limite, queremos mais precisamente compreender esse conceito dentro do lugar-limite no qual ele é inserido: no último capítulo da Analítica Transcendental. Desse modo, será possível mostrar que a força racional de ir além da experiência tem uma índole crítica imediatamente vinculada à atividade de decomposição de conceitos, sendo, portanto, anterior ao processo peculiar da dialética e, por conseguinte, sendo originalmente $^{5}$ independente do interesse prático.

Nossa proposta, num primeiro momento, mostra como a introdução da divisão fenômeno e númeno significa uma tensão no sentido de Analítica Transcendental uma vez que, além das condições de verdade, expõe também as condições de um engano específico distinto do produzido pelas inferências da razão. Num segundo momento, abordamos mais precisamente o conteúdo do capítulo III da Analítica dos Princípios. Nossa intenção é mostrar como, à luz de uma transgressão natural e inevitável dos limites do conhecimento, Kant estabelecerá um alargamento do entendimento enquanto capacidade de pensar.

\section{A Analítica transcendental seria apenas uma analítica da verdade?}

Kant justifica o nome de Lógica transcendental e sua divisão em Analítica e Dialética por meio de um espelhamento com a Lógica geral. Desse modo, a Analítica dos Conceitos é atribuída ao entendimento enquanto faculdade específica de elaborar regras, e a Analítica dos Princípios é atribuída à faculdade de julgar. A razão enquanto faculdade específica, por sua vez, faz parte apenas da Dialética porque o uso de seus princípios específicos em busca do incondicionado engendra inevitavelmente ilusões. Desse modo, as duas partes da Analítica e a Dialética abarcam as três faculdades de superiores, respectivamente: entendimento, faculdade de julgar e razão. Obviamente, não se trata de afirmar que uma faculdade opera sem outra, mas

\footnotetext{
${ }^{4}$ Essa oposição entre o efeito da crítica para uma razão pura e para a razão especulativa está explicitada no prefácio à segunda edição da seguinte maneira: "Apesar desta importante transformação no campo das ciências e da perda que a razão especulativa tem que sofrer no que até agora imaginava ser sua propriedade, em relação às coisas humanas e ao proveito que o mundo até agora extraiu das doutrinas da razão pura tudo se mantém no mesmo estado vantajoso em que antes se encontrava" (BXXXIXXXII). Ainda sobre tal ambivalência, nas palavras de Licht: "o limite imposto à razão não significa senão a abertura para a realização plena, por outro caminho, da vocação da razão em ir além da experiência possível” (LICHT, 2008 p. 145); cf. também seu comentário a respeito do interesse de certos intérpretes imediatos da obra - por exemplo, Garve e Schulze - em reduzir tal sentido a uma mera proibição da metafísica.

5 Como se sabe o conceito de númeno abre o percurso do domínio prático, segundo a indicação do prefácio à CRPrat. Entretanto, utilizar as consequências práticas do conceito de númeno para legitimar o seu lugar numa analítica transcendental sobre a razão especulativa engendraria não só um primado da razão prática, mas sim um despotismo.
}

JÚNIOR, Paulo Borges de Santana. Os dois lados do limite da crítica: por que o númeno faz parte da Analítica?. Griot : Revista de Filosofia, Amargosa - BA, v.22 n.1, p.34-48, fevereiro, 2022. 
sim de enfatizar o protagonismo de cada uma, contemplando de alguma maneira a qualidade de fio condutor atribuída à Lógica Geral. Nesse espelhamento entre Lógica Transcendental e Lógica Geral, a Analítica dos Princípios, fornecendo o cânone para o uso dos princípios do entendimento, seria concebida de maneira mais rigorosa como uma doutrina da faculdade de julgar (A132/B171).

Esse lugar intermediário para a faculdade de julgar serve também como momento em que a Lógica Transcendental deixaria de simplesmente buscar os conceitos elementares para expor o uso desses mesmos conceitos ${ }^{6}$. No entanto, se levarmos essa característica sistemática da Analítica de maneira inflexível, a introdução do conceito de númeno no seu terceiro capítulo causaria por si mesma uma evidente confusão. Nesse capítulo, uma das intenções explícitas de Kant é atribuir um significado transcendental ao conceito puro do entendimento, mesmo quando tal conceito não tem uso nem empírico nem transcendental. A divisão dos objetos em geral enquanto númenos e fenômenos não faz parte da atividade de subsumir da faculdade de julgar, por isso, seu lugar na Analítica dos Princípios poderia ser, em certa medida, posto em xeque. Além disso, há um lapso de Kant que na introdução da Analítica dos Princípios informa a presença de apenas dois capítulos.

Esta doutrina transcendental da faculdade de julgar deverá conter dois capítulos: o primeiro, que trata da condição sensível, a única que permite o uso dos conceitos do entendimento, isto é, do esquematismo do entendimento puro; o segundo, que trata dos juízos sintéticos que decorrem a priori, sob essas condições, dos conceitos puros do entendimento e que constituem o fundamento de todos os outros conhecimentos a priori, ou seja, dos princípios do entendimento puro (A136/B175).

A divisão entre númeno e fenômeno não faz referência à condição sensível, tampouco é capaz de constituir um juízo sintético a priori, portanto, tal divisão não caberia como desenvolvimento direto de nenhum dos capítulos anteriores. Desse modo, a simples presença de um texto que trate do númeno não parece respeitar a sistematicidade das divisões do livro. De imediato, ao invés de entrar em discussões sobre a gênese da Analítica dos Princípios e afirmar que o capítulo III seria um acréscimo posterior ${ }^{7}$, nossa intenção é compreender o lugar desse texto que estabelece o sentido de um conceito cujo uso seria transcendental e ilegítimo. Em vista disso, elencamos a seguinte questão: Por que o conceito de númeno não é introduzido apenas pela Dialética?

Se o conceito de númeno fosse usado na determinação de um objeto causaria o engano de pretender conhecer o que as coisas seriam em si mesmas, mas tal engano seria, por sua vez, engendrado pelo próprio entendimento - não pela razão. $O$ engano especificamente causado pela razão decorre da aparência projetada de um incondicionado inferido a partir de séries de representações consideradas condições ${ }^{8}$. Eis a ilusão a ser trabalhada propriamente pela Dialética. O conceito de númeno, por sua vez, não causa a ilusão do incondicionado tampouco uma contradição direta na representação do objeto de conhecimento. Ou seja, é possível

\footnotetext{
6 "Só até aqui [no fim da analítica dos conceitos] considerei necessária a divisão em parágrafos, pois tínhamos de tratar dos conceitos elementares. Agora, que [na analítica dos princípios] vamos mostrar o seu uso, a exposição poderá desenvolver-se continuamente, sem necessidade de parágrafos" B169.

${ }^{7} \mathrm{Ou}$ - o que seria mais difícil - perguntar como tal lapso conseguiu se manter intacto na segunda edição da CRP.

8 “As ideias transcendentais servem apenas para ascender na série das condições até ao incondicionado. Relativamente à descida para o condicionado, a razão faz, sem dúvida, um largo uso lógico das leis do entendimento, sem que haja um uso transcendental, e se formamos uma ideia da totalidade absoluta de tal síntese (do progressus), por exemplo da série completa de todas as mudanças futuras do mundo, tal ideia será apenas um ser de razão (ens rationis), só arbitrariamente pensado e não necessariamente pressuposto pela razão" A $336-37$ B 394.
}

JÚNIOR, Paulo Borges de Santana. Os dois lados do limite da crítica: por que o númeno faz parte da Analítica?. Griot : Revista de Filosofia, Amargosa - BA, v.22 n.1, p.34-48, fevereiro, 2022. 
representar (como faz um pensamento pré-crítico) o conhecimento dos objetos como conhecimento das coisas em si mesmas sem gerar contradições ou antinomias, mas nesse caso o conhecimento está mergulhado no realismo transcendental, sendo impossível o estabelecimento de seus limites e de seus fundamentos, ou mais precisamente, contrariando as conclusões da Estética Transcendental. Se a Analítica não trata da ilusão provocada pelo incondicionado, ela, porém, assume a tarefa de tratar de um "engano [Täuschung], no fundo, difícil de evitar" (B305/ausente em A). Tal engano, em vez de causado por uma ilusão transcendental, é causado pela representação de um objeto em geral $^{9}$.

Assim a fronteira entre o engano da razão e o do entendimento se esclarece quando a origem do engano é a representação de um incondicionado (inferido da série das condições) ou é a simples representação de um objeto em geral (encontrado por decomposição ou abstração diretamente das representações presentes no conhecimento empírico). Ao incorporar dentro da Analítica essa fronteira, Kant lhe proporciona um significado maior do que o de uma Lógica da verdade $^{10}$. Esse sinuoso movimento da Analítica para além do que ela inicialmente se propusera se explicita ainda mais na introdução da tábua do Nada.

Antes de abandonar a analítica transcendental, devemos ainda acrescentar algo que, não sendo embora em si mesmo de particular importância, todavia poderia parecer necessário para o sistema ficar completo. O conceito mais elevado, pelo qual é usual iniciar uma filosofia transcendental, é o da divisão em possível e impossível. Como, porém, toda a divisão pressupõe um conceito dividido, deverá indicar-se outro, ainda superior, e esse é o conceito de um objeto em geral (considerado em sentido problemático, sem decidir se é alguma coisa ou nada). Visto as categorias serem os únicos conceitos que se referem a objetos em geral, para se destrinçar se um objeto será algo ou nada, deverá proceder-se segundo a ordem e a divisão das categorias (A 290; B $347)$.

Interpretamos essa hesitação acerca de algo "necessário para o sistema ficar completo" e simultaneamente "em si mesmo [sem] particular importância" como a consciência de Kant de uma tensão entre a sua definição primeira de Analítica Transcendental, tensão, porém, necessária para que o sistema abarque completamente as categorias e os seus usos. A analítica deve decompor exaustivamente o conhecimento do entendimento; em nome dessa decomposição completa, a distinção entre possível e impossível (o princípio lógico clássico) é considerada insuficiente e derivada de uma representação mais originária: representação de objeto em geral. Em outras palavras, para colocar a questão sobre a possibilidade lógica de algo, seria pressuposto a representação desse algo como objeto em geral ${ }^{11}$. Sendo o objeto em geral uma representação alcançada por decomposição de um conhecimento do entendimento (e não através da inferência derivada de uma série de condições), ele precisa permanecer na Analítica, juntamente com o fundamento da distinção dos objetos em geral ${ }^{12}$.

\footnotetext{
${ }^{9} \mathrm{Na}$ introdução da Dialética Transcendental, Kant distingue explicitamente o erro decorrente da ilusão transcendental e o erro decorrente "[d]o uso ou [d]o abuso transcendental das categorias, que é um mero erro da faculdade de julgar" (A 296 B 352 ). O primeiro é especificamente o assunto dessa Dialética e, a nosso ver, o segundo seria o erro a ser evitado dentro dos limites da Analítica dos Princípios (apoiada pela Estética transcendental) enquanto doutrina transcendental da faculdade de julgar.

${ }^{10}$ Essa ampliação do sentido de lógica da verdade e essa distinção com o engano da razão se perdem quando se afirma, como o faz Allison, que tal capítulo "serve essencialmente tanto como um sumário dos resultados da Analítica quanto uma introdução à Dialética" (ALLISON, 1968; p. 180).

${ }^{11}$ Sobre a possibilidade de o objeto em geral, substituindo o conceito de coisa em geral, abrir espaço para uma nova ontologia, cf. CODATO 2009.

12 Note-se que não conseguimos resolver completamente o problema sistemático das divisões do livro. Por ser uma representação originária, caberia ao conceito de númeno um lugar na analítica transcendental, mas dentro da divisão entre analítica dos
}

JÚNIOR, Paulo Borges de Santana. Os dois lados do limite da crítica: por que o númeno faz parte da Analítica?. Griot : Revista de Filosofia, Amargosa - BA, v.22 n.1, p.34-48, fevereiro, 2022. 
Apesar de constituir um capítulo, o fundamento da distinção entre númenos e fenômenos não tem a intenção de introduzir na Analítica transcendental princípios ou elementos que ampliassem o domínio do conhecimento. Pelo contrário, a intenção de recuperar sumariamente alguns momentos de toda a Analítica se apresenta em sua primeira alínea junto com a especificação de que não haverá, no entanto, nenhuma solução nova, mas apenas a tentativa de reforçar uma convicção ${ }^{13}$. Identificamos, dessa maneira, que o conceito de númeno se enlaça com uma preocupação mais forte com o modo de ver ou de revisitar o resultado de toda a Analítica, preocupação que pareceria ser expressa de maneira mais adequada enquanto nota ou observação. No entanto, em vez de sugerir uma correção ao autor ${ }^{14}$, nos parece mais fecundo aceitar sua sugestão e compreender como esse texto - enquanto um capítulo específico - acaba por constituir uma ampliação no sentido primeiro de analítica da verdade, que, agora, absorve a demanda de impedir a representação positiva de um númeno na intuição de um objeto ${ }^{15}$.

Desse modo, a Analítica Transcendental realiza mais do que a sua definição preliminar prometia, ou em outras palavras, o exercício de decomposição dos conhecimentos alcança algo a mais do que a exposição das condições da verdade, incluindo o significado transcendental das categorias e as representações tipificadas do nada. Diante do espelhamento com a Lógica Geral $^{16}$, ela se apresentava inicialmente como a lógica da verdade que simplesmente decomporia o conhecimento empírico em conceitos puros do entendimento, porém, ao término, alcançando a representação de um objeto em geral e sua divisão em fenômenos e númenos, assume-se uma questão que ultrapassa a preocupação com a verdade em direção a uma visão em geral, ou poderíamos dizer, totalizante, referente aos limites do conhecimento. Em resumo, esse esforço de ver e mostrar o próprio limite da esfera dos objetos como um todo, numa perspectiva crítica, faz a Analítica Transcendental expor, junto com as condições de verdade, as condições de um engano cuja peculiaridade seria ter origem diretamente nas próprias categorias.

\section{A transgressão e o alargamento negativo}

Do problema sistemático do capítulo III para a Analítica dos princípios, passemos agora ao conteúdo desse capítulo. Seu início traz justamente uma abordagem metafórica da

\footnotetext{
conceitos e analítica dos princípios, esse capítulo, negando completamente o uso do conceito de númeno, seria mais compatível com a primeira parte.

13 “Embora já ao longo da Analítica tivéssemos dado suficiente resposta a estas interrogações, uma revista sumária das soluções dadas pode reforçar a convicção, reunindo num só ponto os seus momentos" (A236 B295).

14 A título de comparação, poderíamos dizer que o modo como Seel considera a Analítica dos Princípios aposta em incoerências da posição desse capítulo. Segundo Seel, o terceiro capítulo "não pertence realmente à doutrina da faculdade de julgar transcendental, mas antes forma uma espécie de conclusão para toda a analítica transcendental, que Kant provavelmente incluiu no segundo livro apenas porque não era suficientemente extensa para criar um livro próprio e, sobretudo, porque, como um livro próprio, teria perturbado a arquitetônica da analítica transcendental, que estava orientada para a faculdade superior do conhecimento" (SEEL, 1998; p. 220). Seu comentário ainda afirma que o capítulo do Esquematismo deveria ser contido na Analítica dos Conceitos (p.225). Nossa intenção não é minimizar a pertinência das questões colocadas pelo intérprete (às quais não responderemos), mas apenas buscar uma perspectiva que veja nas supostas incoerências o princípio racional seguido por Kant.

15 A nosso ver, tal ampliação não precisa se reduzir a ocupação do papel da ontologia. "As suas proposições fundamentais são apenas princípios da exposição dos fenômenos e o orgulhoso nome de ontologia, que se arroga a pretensão de oferecer, em doutrina sistemática, conhecimentos sintéticos a priori das coisas em si (por ex. o princípio da causalidade) tem de ser substituído pela mais modesta denominação de simples analítica do entendimento puro" A 247 B303. Nossa proposta é que tal ampliação da analítica decorre justamente de sua atividade de decompor a faculdade do entendimento de um modo tão exaustivo que inclui a categoria do númeno e ainda a tábua do Nada.

16 Esse espelhamento da investigação transcendental com a lógica geral é bastante explorado por Kant nos textos introdutórios tanto à Lógica Transcendental quanto da Analítica dos Princípios Cf. A50-64 B74-88 e A130-132 B169-171.
}

JÚNIOR, Paulo Borges de Santana. Os dois lados do limite da crítica: por que o númeno faz parte da Analítica?. Griot : Revista de Filosofia, Amargosa - BA, v.22 n.1, p.34-48, fevereiro, 2022. 
transgressão da razão especulativa. Ironicamente, o capítulo que vimos transgredir o sentido de lógica da verdade alude à transgressão especulativa da razão, e a essa ironia soma-se a dificuldade do registro imagético. Em todo caso, reconhecendo, mas não aprofundando tal dificuldade, nossa intenção se restringe à problemática em torno da postura crítica diante do limite imposto por ela ao conhecimento.

Em nome de uma convicção maior a respeito dos limites estabelecidos, Kant descreve o percurso para além do país/terra [Land] do entendimento; país que se descobriu uma ilha. Desse modo, a divisão fenômeno-númeno é associada à finalidade de retrabalhar, com mais cuidado, a imagem e o significado da delimitação do entendimento, a qual, em vez de extirpar completamente tal transgressão, visa a alguma maneira legítima de expressão. Portanto, ao trabalho de impor um limite, associa-se claramente o trabalho de extrair, de tal limite, um sentido mais largo em vista de um sistema da razão pura e em vista ainda de um projeto idealizado enquanto crítico. A crítica desenha o limite e nisso se distingue da postura doutrinal, mas, através da afirmação de sua qualidade transcendental, ela contorna toda a esfera do saber sem, contudo, permanecer presa do lado de dentro. $O$ traço do limite, ainda que não possua efetivamente uma dimensão, representa a vantagem da investigação crítica sobre o desenvolvimento doutrinal do conhecimento ${ }^{17}$.

É bastante conhecida a maneira pela qual Kant descreve a ilha do entendimento cercada de numerosos obstáculos e ilusões que alimentam esperanças vazias ao navegante que sonha, apesar de todos os insucessos metafísicos, explorar essas águas e descobrir novas terras. Ao lembrarmos essa metáfora, poderíamos prontamente pensar que o autor proibisse categoricamente esse navegante, indicando-lhe o dever de permanecer nos limites dessa ilha. Todavia, acontece o contrário. Encontramos a confissão de que, de tais "aventuras, [o navegante] não consegue nunca desistir nem nunca levar a cabo" (A236/B295) ${ }^{18}$. Mesmo que ultrapassar os limites do entendimento seja um ato nebuloso, ilusório, vazio, onírico, tal viagem continuaria sempre a provocar no sujeito uma vontade de prosseguir. Assim, no lugar de abolir essa transgressão eternamente desejada, identifica-se sutilmente a intenção de transformá-la, ou seja, de fornecer outra expressão em que essa inevitável viagem para além do conhecimento não caia em contradições tampouco confunda miragens com terra firme.

A presença desse aspecto volitivo do ânimo causa novamente um incômodo quanto aos limites da própria Analítica transcendental. Nas palavras de Kant "não basta simplesmente expor o que é verdadeiro, mas [é preciso expor] ainda o que se quer [begehrt] saber" (A237). Essa formulação reforça novamente a necessidade de a Analítica Transcendental ser mais do que a lógica (ou a exposição das condições) da verdade, mas também já avança demasiadamente para além de sua característica enquanto decomposição do conhecimento nos elementos puros do entendimento. A Analítica se precipita ao problema acerca do conflito da razão correspondente à introdução da intencionalidade na faculdade de conhecimento. Entretanto, no decorrer do capítulo, Kant recua nessa exposição do que a razão quer saber, concentrando-se, por meio do esforço analítico, em convencer tal razão que a interferência de uma vontade impediria a legitimação a priori do seu próprio saber. A razão especulativa, além de pura em relação ao que é empírico, precisa ser pura também em relação aos seus próprios interesses.

\footnotetext{
${ }_{17}$ Nos Prolegômenos §57, Kant tenta expressar essa vantagem da crítica a partir da distinção entre Schrank e Grenze e da imagem geométrica da linha que limita uma esfera. Ainda que tal distinção não seja sempre respeitada por Kant - Cf. LONGUENESSE, 1993; 337-8 - é importante que o limite imposto pela crítica transcendental contenha sempre essa composição entre positivo e negativo, possuindo sempre duas direções, sempre dois lados.

18 Para uma relação dessa imagem com a objeção aos empiristas de que eles conduziriam o barco para encalhar na praia (presente na Introdução aos Prolegômenos), cf. dos SANTOS 1994 pp 251-347.
}

JÚNIOR, Paulo Borges de Santana. Os dois lados do limite da crítica: por que o númeno faz parte da Analítica?. Griot : Revista de Filosofia, Amargosa - BA, v.22 n.1, p.34-48, fevereiro, 2022. 
Em poucas palavras, dessa metáfora da ilha do conhecimento é extraído um conflito entre o conhecimento legitimamente fundamentado e o desejo de conhecer. Consequentemente, é necessário, por um lado, aceitar a limitação do conhecimento (teórico) e, por outro, enredar aquele desejo na promessa de uma vantagem cuja anunciação, por sua vez, envolve um suspense - talvez justamente porque o conteúdo positivo dessa promessa não possa habitar adequadamente uma analítica da razão pura ${ }^{19}$.

\begin{abstract}
Se, mediante esta investigação crítica, nada mais aprendermos do que aquilo que por nós teríamos verificado no uso empírico do entendimento e mesmo sem qualquer investigação tão subtil, parece que o seu benefício não compensaria os esforços e os preparativos. (A 237 B296)
\end{abstract}

Afirmar um limite e delinear uma fronteira entre o fundamento do conhecimento e o querer conhecer se torna um modo de preservar demandas irredutíveis, mas que pertencem igualmente a um mesmo ânimo. Sendo assim, esse capítulo serve tanto para reafirmar o uso empírico das categorias (tese já estabelecida anteriormente) quanto para indicar a maneira de pensar pela qual se permita e se fundamente, observando as advertências da crítica, uma representação racionalmente significativa para além do sensível. Esse segundo ponto parece ser, ao mesmo tempo, a especificidade desse capítulo e o elemento que escapa à definição de uma lógica da verdade.

Esse querer saber mais do que é dado pela experiência imediata é natural e inextirpável para a razão, por isso, ele precisa ter uma característica transcendental, ou seja, não pode se perder nem pelas simples formas lógicas dos conceitos tampouco pelas paixões particulares de imagens ou ilusões grandiosas. A esse querer, uma lógica da verdade forneceria mais do que promessas vazias? Na verdade, a crítica parece impor junto com os seus limites uma suspensão do querer (provisória, mas fundamental) em favor de uma visão sobre a totalidade do domínio do conhecimento. Tentando, então, evitar aqueles dois caminhos opostos (o do dogmático e o do gênio) que poderiam se explicar reciprocamente ${ }^{20}$, mas sem cair por sua vez na suspensão cética do juízo, a postura crítica afirmará o seu nível transcendental e seu direito de se colocar num nível distinto do conhecimento por ela permitido, ou seja, num nível acima do uso empírico das categorias.

A investigação transcendental possui um desnível em relação ao seu resultado: a crítica transcendental determina a legitimidade do entendimento apenas em seu uso empírico. Se, por um lado, ela demonstra que os conceitos são produzidos a priori, por outro, a crítica aponta a carência de sentido quando tais conceitos não se referem de nenhuma forma à intuição empírica $^{21}$. A restrição da categoria ao uso empírico é tão forte que mesmo a matemática não poderia se furtar completamente de construir figuras ou de utilizar os dedos sem perder sua validade (A240 B299). É a referência ao empírico que fornece às representações criadas a priori

\footnotetext{
19 Ao contrário, da formulação do Prefácio à segunda edição, onde a ampliação do pensamento para além do conhecimento é ligada diretamente a uma fé e ao campo moral. Nossa sugestão, porém, em vez de tratar a transição entre o negativo e o positivo indicada nesse Prefácio, seria compreender melhor o significado desse negativo à luz do capítulo III da Analítica, capítulo que nos parece conter a maior parte dos fundamentos da longa alínea que trata justamente do "tesouro" da crítica (CI BXXIVXXXI). Para uma interpretação dessa passagem à luz da forma reflexiva do juízo, cf. KEINERT 2006, pp. 71-83.

20 Cf. Sonhos de um visionário (...) e Sobre um enaltecido tom (...).

21 "Ora, só na intuição se pode dar um objeto a um conceito e, embora uma intuição pura seja possível para nós a priori, mesmo anteriormente ao objeto, também essa intuição só pode receber o seu objeto e, portanto, validade objetiva por intermédio da intuição empírica de que é simplesmente a forma" (A239 B298).
}

JÚNIOR, Paulo Borges de Santana. Os dois lados do limite da crítica: por que o númeno faz parte da Analítica?. Griot : Revista de Filosofia, Amargosa - BA, v.22 n.1, p.34-48, fevereiro, 2022. 
pelo entendimento "um sentido, isto é, uma significação ${ }^{22 "}$, e, mais ainda, sem um uso empírico das categorias, não haveria propriamente objetividade, e as representações seriam sempre um mero jogo (A239 B298).

É surpreendente essa ênfase inicial em prender o sentido da categoria totalmente dentro do uso empírico (ou da realidade objetiva), conduzindo-nos aparentemente a uma identificação entre a sua questão de sentido e a sua questão de verdade. Todavia, não é menos forte a completa inversão no argumento durante o decorrer desse capítulo, onde se estabelece também um significado transcendental das categorias. Em poucas palavras, a dificuldade está em compreender a hierarquia (e não a simetria $^{23}$ ) entre as duas exigências para o conceito: "primeiramente a forma lógica de um conceito (do pensamento) em geral, e segundo lugar [zweitens] a possibilidade de lhe dar um objeto a que se refira" (A239). Assim sendo, se a questão de sentido pode - contra os metafísicos ${ }^{24}$ - denunciar a carência de validade objetiva de suas noções, a questão da verdade, ao contrário, não pode ser propriamente condição para a questão de sentido das categorias do entendimento puro. Apesar de insistir na restrição contra o uso transcendental das categorias, elas, ao fim, terão o seu sentido transcendental ${ }^{25}$, abrindo espaço para sua distinção com a questão de verdade (realidade), uma vez que a esfera do pensar será ampliada, sem acrescentar nada à esfera dos objetos. Em suma, os conceitos puros do entendimento, mesmo sem a sensibilidade, são capazes de ter relação com um objeto em geral no pensamento $(\mathrm{A} 248)^{26}$.

Nos meandros entre uso empírico e significado transcendental das categorias, o capítulo III revela a intenção e a ação de transitar entre a perspectiva do conhecimento e uma que lhe seja completamente distinta mas, em alguma medida, complementar. A partir dessa perspectiva

\footnotetext{
${ }^{22}$ Em A240 B299, Kant utiliza claramente equivocidade da palavra "sentido" para indicar que o significado da categoria estaria vinculado à sensibilidade. Em A242 (suprimido em B), Kant reafirma essa união entre questão de significação e questão de validade objetiva, ao frisar que as categorias não "podem ter alguma significação e validade objetiva no entendimento puro, sem a sensibilidade". Essa identificação ocorre em virtude do que Kant diz ser uma definição real [Realerklärung] que "seria então aquela, que torna evidente [deutlich] não meramente um conceito, mas ao mesmo tempo a sua realidade objetiva".

23 Acreditamos que a interpretação de Zöller - que retoma a proibição do uso transcendental para compreender a relação "multiforme e complexa" entre transcendental e empírico - deixa escapar essa hierarquia em prol da "identificação clandestina entre o empírico enquanto transcendentalmente possibilitado e o transcendental enquanto empiricamente realizado" (ZÖLLER, 2017 ; p.112). Embora concordemos com a necessidade de pensar o empírico como algo possibilitado pelo transcendental, não nos parece necessário reduzir a perspectiva transcendental à sua tarefa de realizar-se na experiência. Mesmo considerando crucial a diferença entre origem e uso das categorias para a perspectiva transcendental de Kant, Zöller argumenta que "a realização do $a$ priori através da possibilitação da experiência é também uma restrição. A realização das formas a priori na formação principal da experiência se revela ser a única maneira de as realizar (num contexto teorético-cognitivo). Qualquer outra realização é apenas ilusória e imaginária" (p.104).

${ }^{24}$ Como explica Lebrun, essa ênfase na questão do sentido como anterior à relação objetiva significa uma preocupação crítica em ruptura com a metafísica clássica. Cf. LEBRUN, 2002, 70-74. "A palavra 'vazio' (sinnleer) não queria dizer nada para ela [metafísica clássica]. Já que o sentido era apenas a sombra da coisa dada na intuição intelectual, por que se teria inquietado em saber se a simples significação de uma palavra se relacionava ou não com um objeto, ou podia ou não se relacionar com 'alguma coisa em geral'?" (p.73). Na mesma linha de argumentação, referindo-se mais especificamente à tradição lógica, Caimi afirma: "que um conceito, para não ser vazio, precise de um conteúdo é algo inteiramente novo em um momento da História da Filosofia no qual impera a lógica leibniziano-wolffiana. Nela só se entendia como conceito vazio aquele que não admitisse conteúdo nenhum porque não era, ele mesmo, um conceito: porque encerrava uma contradição interna ou algum outro defeito formal, que o inabilitava como conceito" (CAIMI, 2001, p. 189).

25 Para uma posição divergente, Cf. KEMP-SMITH 2003, 412-14) que considera essas oscilações como uma transição do pensamento de Kant cuja maturidade seria justamente iguala o significado da categoria com a sua aplicação. Nossa posição é diametralmente oposta, e consideramos tais oscilações justamente um sinal da maturidade do projeto crítico que, além de sua objeção à ontologia clássica, já pensa em abrir caminho para o pensamento prático. E no que tange às modificações da segunda edição, a nota ao $§ 27$ da dedução B (B166) é clara em preparar essa diferença entre significação e aplicação das categorias, ou para ser mais exato, entre a aplicação das categorias no uso teórico e a possibilidade de tais categorias conseguirem encontrar uma aplicação diferente.

26 “As categorias no pensamento não são limitadas pelas condições da nossa intuição sensível; têm um campo ilimitado e só no conhecimento daquilo que pensamos, a determinação do objeto, tem necessidade de intuição" (B166, ausente em A).
}

JÚNIOR, Paulo Borges de Santana. Os dois lados do limite da crítica: por que o númeno faz parte da Analítica?. Griot : Revista de Filosofia, Amargosa - BA, v.22 n.1, p.34-48, fevereiro, 2022. 
movente, é possível (re)avaliar ou recolocar a vantagem de um trabalho transcendental em relação a um trabalho meramente empírico que tivesse como resultado essa mesma limitação do uso das categorias. Através da afirmação de sua qualidade transcendental, a crítica, já nos limites de uma analítica do entendimento, se permite ultrapassar o nível do propriamente verdadeiro, primeiramente em relação às suas condições (as representações transcendentais para a determinação dos fenômenos), e, em segundo lugar, em relação a conceitos que estão fora dessas condições (em relação à possibilidade de pensar objetos cuja realidade fosse irredutível à ou inabarcável pela realidade fenomênica).

Embora seu resultado seja a limitação do uso empírico das categorias, a crítica, em função da qualidade transcendental, fornece ao limite estabelecido uma função dupla: "saber o que é possível encontrar dentro ou fora da esfera inteira" (A238/B 297). Enquanto uma investigação empírica sobre os limites precisaria se contentar com a parte interna desse limite e ignorar quaisquer representações que se projetassem de ou para fora, a transcendental lhe transpassa e vislumbra também o aspecto externo desse limite. Na verdade, esse desnível indica que o resultado é defasado em relação à atividade, ou mais precisamente, indica que o poder de pensar (ou representar) na perspectiva crítica transpassa as limitações, as fronteiras ou as balizas do conhecimento puro.

Em suma, o que está circunscrito no interior dos limites, ou seja, o uso empírico das categorias, corresponde à fonte de objetividade e à nossa possibilidade de determinar um objeto na intuição. Tais limites retratam a demarcação do domínio da intuição sensível, que permite às categorias encontrar um objeto que pode ser devidamente subsumido pela faculdade de julgar e, consequentemente, atestam a realidade objetiva para um conhecimento teórico.

[...] não podemos dar uma definição real de nenhuma das [categorias], isto é, tornar compreensível a possibilidade do seu objeto, sem nos reportarmos, em seguida, às condições da sensibilidade, portanto à forma dos fenômenos; essas categorias precisam ser limitadas aos fenômenos enquanto seus únicos objetos, porque, retirada esta condição, desaparece todo o significado, ou seja, toda a relação com o objeto, e já não haverá um exemplo que possa tornar apreensível o que seria propriamente pensado sob tais conceitos para uma coisa.( A240-1 B300, adp)

A definição das categorias presentes na Dedução Transcendental é caracterizada por Kant como real, ou seja, uma definição que, além do critério da exposição do conceito, contempla a sua realidade objetiva (A242, suprimido em B). Assim, em função dessa realidade objetiva, a categoria tem seu significado vinculado completamente às formas da sensibilidade e ao uso empírico. Contudo, a qualidade transcendental da investigação e a expectativa de jogar luz para além do que está dentro dos limites da intuição fazem Kant se dirigir ao mero pensar identificando que os conceitos puros do entendimento se referem ao objeto de duas formas distintas: uma referência a um objeto determinado (numa intuição possível) e uma referência ao objeto em geral ${ }^{27}$ (no mero pensamento). No primeiro caso, há uma atividade completa de subsunção da faculdade de julgar e um uso efetivo da categoria, enquanto no segundo, sendo impossíveis essa subsunção e um uso da categoria, restaria, o seu significado transcendental, um significado que não seria mais considerado dentro dos limites da questão de realidade objetiva.

\footnotetext{
27 “O pensar é o ato de referir a um objeto uma intuição dada. (...) Mediante uma categoria pura, na qual se abstraiu de toda a condição da intuição sensível, única que nos é possível, não é determinado nenhum objeto, apenas se exprime o pensar de um objeto em geral, segundo diversos modos" (A 247 B304).
}

JÚNIOR, Paulo Borges de Santana. Os dois lados do limite da crítica: por que o númeno faz parte da Analítica?. Griot : Revista de Filosofia, Amargosa - BA, v.22 n.1, p.34-48, fevereiro, 2022. 
Pode ser, pois, aconselhável exprimirmo-nos do seguinte modo: as categorias puras, sem as condições formais da sensibilidade, têm significado apenas transcendental, mas não possuem uso transcendental, porque este uso é, em si mesmo, impossível, na medida em que lhe faltam todas as condições para qualquer uso (nos juízos), ou seja, as condições formais da subsunção de um eventual objeto nesses conceitos. (A248/B 305)

Portanto, em vista de projetar luz para além dos limites internos do conhecimento, o sentido das categorias, subordinado num primeiro momento exclusivamente ao seu uso empírico, consegue se afirmar, ainda dentro da Analítica, enquanto sentido transcendental no campo do mero pensar. Uma vez que tem origem no entendimento, a categoria guardaria ainda uma possibilidade de significado transcendental, no qual ela se limita a uma simples função lógica ${ }^{28}$ incapaz de representar algo enquanto objeto determinado. $\mathrm{O}$ preço do significado transcendental das categorias seria, desse modo, colocar-se para além da possibilidade de subsumir um objeto. Ainda caberia indicar que, a partir dessa perspectiva externa concernente ao limite do uso empírico da categoria, é a faculdade de julgar, que, desse modo, assumirá mais propriamente o papel restritivo, fornecendo a compreensão de que, em vez de limitado pela sensibilidade, o limite do uso teórico das categorias seria mais propriamente a atividade de subsunção, sem a qual nenhum objeto seria determinado. A sensibilidade não limita propriamente os conceitos do entendimento; quem o faz é a faculdade de julgar (sua subsunção). A intenção de Kant com essa investida, através do significado transcendental da categoria e de sua possibilidade de pensar um objeto em geral, é marcar a sua passagem para além da intuição sensível e, consequentemente, para além da própria esfera dos objetos ${ }^{29}$.

Esse significado referente a um objeto em geral é, desse modo, capaz de evitar o efeito enganoso que poderia advir do conceito de númeno. A estranha designação de númeno enquanto um conceito-limite [Grenzbegriff] provavelmente alude à peculiaridade desse conceito puro do entendimento em relação às categorias puras listadas pela dedução transcendental. Por um lado, o númeno é um conceito que não tem propriamente uma aplicação ou um uso como tais categorias, mas, por outro lado, não é uma ideia da razão, ou seja, um conceito produzido pela busca do incondicionado dentro de uma série de condições. A posição sistemática na $C R P$ desse capítulo, que trata de um engano que não pertence à Dialética, representa por si mesma o limite entre essas duas partes da Lógica Transcendental. Aqui não se trata mais da legitimação dos conceitos puros do entendimento nem da descrição dos usos de tais conceitos nos juízos, mas tampouco se trata ainda da explicação ou da descrição específica das ilusões transcendentais da razão. Portanto, o capítulo III retrata a transgressão da razão especulativa da perspectiva desse limite onde é possível ver simultaneamente os dois lados, tanto o da verdade quanto o do engano.

O númeno é um conceito-limite na medida em que, realizando a abstração das condições formais da sensibilidade, não possui uso nem empírico nem transcendental, mas que preserva,

\footnotetext{
28 "Para cada conceito, exige-se primeiro a forma lógica de um conceito (do pensamento) em geral, e em segundo lugar a possibilidade de lhe dar um objeto a que se refira. Sem este último, não possui sentido e é completamente vazio de conteúdo, embora possa conter ainda a função lógica de formar um conceito a partir de certos dados" (A239 B298). Essa divisão se aproxima da tentativa de Bunch em explicar a dedução B por meio da divisão entre "validade objetiva" e "realidade objetiva". Segundo esse intérprete, a realidade objetiva é imediatamente o conteúdo intencional ou representacional de um conceito e, desse modo, não se refere à realidade do objeto referido (BUNCH, 2010, p. 77). A validade objetiva, por sua vez, pertenceria mais ao âmbito lógico ou formal da representação, sendo uma "forma pura da objetividade" que é anterior à aplicação das categorias às intuições, enquanto condição necessária da unidade sintética da apercepção (BUNCH, 2010, p. 68).

29 "Eis porque as categorias têm mais largo âmbito que a intuição sensível, porque pensam objetos em geral, sem considerar o modo particular (da sensibilidade) em que possam ser dados. Mas nem por isso determinam uma maior esfera de objetos, porque é inadmissível que estes possam ser dados, sem pressupor como possível outra intuição diferente da sensível, ao que não estamos de modo algum autorizados" (A254 B309).
}

JÚNIOR, Paulo Borges de Santana. Os dois lados do limite da crítica: por que o númeno faz parte da Analítica?. Griot : Revista de Filosofia, Amargosa - BA, v.22 n.1, p.34-48, fevereiro, 2022. 
mesmo assim, uma significação transcendental ou uma referência ao objeto em geral. Convém atentar para essa dimensão dupla do limite, em outras palavras, convém compreender a relação da razão pura com tais limites à luz desse conceito de um objeto em geral que não está dentro do campo do conhecimento, mas que precisa de alguma forma tocá-lo pelo lado de fora. A posição do númeno na $C R P$, que causa tanta controvérsia para o seu próprio sistema, a nosso ver, expressaria o vínculo da razão pura com algo fora do conhecimento, possibilitando uma transgressão das condições do empírico legitimada pela crítica. Em vez de subordinada ao interesse do conhecimento, é a postura crítica que subordina tal interesse e, consequentemente, direciona a Analítica Transcendental ao fundamento da divisão dos objetos em geral.

Ressaltemos mais uma vez essa capacidade da crítica transcendental de se colocar nos dois lados dos limites do conhecimento, sublinhada claramente no começo desse capítulo.

\begin{abstract}
Há, todavia, uma vantagem que pode compreender e apreciar o mais renitente e menos animoso aprendiz de uma investigação transcendental e que é esta: o entendimento, que apenas se ocupa do seu uso empírico, que não reflete sobre as fontes do seu próprio conhecimento, pode, é certo, progredir muito, mas não pode determinar para si próprio os limites [Grenzen] do seu uso, e saber o que é possível encontrar dentro ou fora da sua esfera inteira, pois para tanto se requerem as indagações profundas que temos realizado. Mas, se não puder distinguir se certas questões se situam ou não no seu horizonte, nunca terá a certeza dos seus direitos e da sua propriedade; terá de contar com muitas e humilhantes correções, sempre que (como é inevitável), transgredir incessantemente os limites do seu domínio e se perder em quimeras e ilusões [Blendwerke] (A237-8 B 297.)
\end{abstract}

A crítica possui uma qualidade transcendental, mas o crítico (juiz da crítica) não exige que o conhecimento, por ele legitimado, alcance necessariamente o campo transcendental. Ele se satisfaz em ver o dentro e o fora da esfera do saber, ou seja, em poder se situar nos dois lados do limite do conhecimento. Assim, ocupando o limite, o crítico consegue ser imparcial, isto é, consegue, por um lado, impedir que o desejo da razão em ir além do empírico projete ilusões fraudulentas no conhecimento e, por outro, consegue impedir que os limites do conhecimento avancem em direção à faculdade de desejar e a seus objetos como liberdade, alma e Deus. Em vez de simbolizada pela cegueira, tal imparcialidade seria mais bem designada enquanto capacidade de ver os dois lados de um processo. Assim, o crítico realizando essas duas ações é imparcial sem estar em cima do muro; na verdade, sua posição marca a certeza quanto aos direitos de cada parte. $O$ crítico é um juiz que nessa posição de limite precisa vigiar e preservar as condições do conhecimento e as pretensões da razão, expressando assim a utilidade negativa que Kant alude tanto no prefácio à segunda edição quanto em outros momentos ${ }^{30}$ da CRP.

Todavia, há algo a mais do que uma utilidade negativa. Há, sem dúvida, uma utilidade que em relação ao conhecimento é negativa por não contribuir constitutivamente com a determinação de um objeto em particular na intuição. No entanto, o alargamento negativo não se reduz a uma ausência ou impossibilidade de saber, tal alargamento é uma força restritiva do entendimento ante a sensibilidade. Para compreender a efetividade dessa força restritiva é necessário se afastar do interesse pelo conhecimento e privilegiar a simples faculdade de representar, atendo-se para a diferença entre o poder das representações que provém do mero pensamento e o que proviria da mera intuição.

\footnotetext{
${ }^{30} \mathrm{Em}$ A382 (suprimido em B), temos que a psicologia racional não pertence ao alargamento do conhecimento, mas que ela seria “um exame crítico dos nossos raciocínios dialéticos". De maneira similar com a teologia transcendental, Cf. A640-B660.
}

JÚNIOR, Paulo Borges de Santana. Os dois lados do limite da crítica: por que o númeno faz parte da Analítica?. Griot : Revista de Filosofia, Amargosa - BA, v.22 n.1, p.34-48, fevereiro, 2022. 
Se retiro de um conhecimento empírico todo o pensamento (por categorias), não resta conhecimento algum de um objeto [Gegenstandes]; pois pela simples intuição nada é pensado, e do fato de haver esta afecção da sensibilidade em mim não constitui nenhuma referência de uma tal representação a um objeto qualquer [auf irgend ein Objekt]. Mas se, pelo contrário, abstraio toda a intuição, resta ainda a forma de pensamento, isto é, o modo de determinar um objeto [Gegenstand] para o diverso de uma intuição possível. Eis porque as categorias prolongam-se bem mais longe [so fern weiter] que a intuição sensível, porque pensam objetos em geral [Objekte überhaupt], sem considerar o modo singular (da sensibilidade) em que possam ser dados (A254 B309)

Quando decompostos totalmente o pensamento e intuição, percebemos que a função originária da referência ao objeto está no entendimento, ainda que a referência concreta dessa função a um objeto particular dependa da sensibilidade. A afecção da sensibilidade em mim não cumpre por si mesma nenhum papel representativo; enquanto mera afecção, a sensação não representa qualquer objeto, isto é, não põe objeto algum diante do sujeito afetado. Um diverso de afecções não seria mais do que modificações imediatas no sujeito. Para a representação de um objeto singular, é necessário tanto intuição quanto pensamento, ao passo que, para a representação de um objeto em geral, basta o pensamento. Assim, o alargamento que a posição crítica concede ao pensamento na Analítica Transcendental é justamente essa capacidade de, por si mesmo, representar os objetos em geral e mais precisamente o direito de nomear a coisa em si como númeno, ou seja, de pensá-la enquanto objeto em geral não sensível. Quando o crítico habita esse limite, ele concede liberdade ao pensamento referente às condições da intuição, legitimando um alargamento da capacidade de pensar irrestrito que, por sua vez, avançará, na segunda Crítica, à faculdade de desejar e, posteriormente na terceira Crítica, ao próprio sentimento de prazer e desprazer.

A impossibilidade de determinar (ou subsumir) um objeto particular para o númeno faz com que a divisão em fenômenos e númenos se refira propriamente aos objetos em geral e marca, consequentemente, uma negatividade em torno do conceito de númeno. Todavia, o fundamento dessa divisão posto na Analítica transcendental marca um alargamento para o entendimento.

O nosso entendimento recebe, deste modo, um alargamento negativo, isto é, não é
limitado pela sensibilidade, mas antes limita a sensibilidade, em virtude de nomear
númenos as coisas em si (não consideradas como fenômenos [Erscheinungen]). Mas logo,
simultaneamente, impõe a si próprio os limites de não as conhecer mediante categorias,
por conseguinte, [impõe-se o limite] de pensá-las apenas sob o nome de algo ignorado
[eines unbekannten Etwas] (A256 B312).

Assim, sem acrescentar novos objetos, esse alargamento negativo - esse direito de designar de númeno as coisas em si mesma representadas como objetos em geral - contribui para uma visão total da razão sobre os limites do conhecimento. Nessa perspectiva, o entendimento está para além da sensibilidade, sendo possível e legítimo que, em vez de limitado pela sensibilidade (limitação válida para o conhecimento de um objeto), ele se represente limitando a sensibilidade. Assim, ele pode impedir que a exigência de condições da intuição (ou seja, as formas de espaço e tempo) se alargue até os objetos inteligíveis, guardando, portanto, para estes rigorosamente nada além de um vazio. Em poucas palavras, o entendimento impõe limites à sensibilidade porque garante que o objeto alçado na posição de númeno não precisa ser submetido à simultaneidade do espaço ou à sucessão do tempo. Encontramos assim na Analítica Transcendental um fundamento para a sugestão do duplo ponto de vista que será, posteriormente, fundamental para uma analítica da razão prática. 
A Analítica Transcendental se apresenta primeiramente enquanto lógica da verdade, mas sua atividade abstrativa de decomposição, além de uma dedução de categorias do entendimento, estabelece também a representação do objeto em geral. Esse último passo será condição para o domínio moral, como a própria Dialética ou o Prefácio à segunda edição explicitam, mas essa intenção precisa se calar durante a Analítica, permanecendo nada mais do que o alargamento do pensamento sobre o conhecimento. Esse terceiro capítulo fornece a visão geral dos limites do conhecimento como uma vantagem negativa para a ciência, mas positiva para a crítica na medida em que coloca o entendimento numa posição acima da sensibilidade. Essa posição equilibrista da crítica possui uma duplicidade incômoda, desde o início, para seus interlocutores. Mas não seria essa capacidade de transitar sobre os dois lados do limite a virtude por excelência de um crítico ou de um juiz? 


\section{Referências}

ALLISON, H. Kant's concept of the transcendental object. In Kant-Studien vol. 59, no. 1-4, Berlin; New York: De Gruyter, 1968 (pp. 165-186)

BUNCH, A. 'Objective Validity' and 'Objective Reality' in Kant's B-deduction of the Categories. In Kantian Review v.14-2. 2010 pp 67-92.

CACCIOLA. Schopenhauer e a Questão do Dogmatismo. São Paulo, Edusp-Fapesp, 1994.

CAIMI, M. Pensamentos sem conteúdo são vazios. In Analytica vol. 6, 2001 (pp. 177-94).

CODATO, L. Kant e o fim da ontologia. In Analytica 13 (1) (2009). 39-64.

HULSHOF, M. O conceito de númeno na "Dialética transcendental": a abertura para um uso legítimo das ideias da razão. Studia Kantiana 10 (12) (2012):5-33.

GUYER, P. Kant and the Claims of Knowledge. New York, Cambridge University Press, 1987.

KANT, I. Gesammelte Schriften. Hsrg. Akademie der Wissenschaften. Berlin/Leipzig: W. de Gruyter.

KANT, I.Crítica da razão pura. Trad. M. P. dos Santos \& A. F. Morujão. Lisboa: Fund. Calouste Gulbenkian. 2001.

KEINERT, Crítica e autonomia em Kant: a forma legislativa entre determinação e reflexão. São Paulo (tese) USP. 2006.

KEMP SMITH, N. A Commentary to Kant's 'Critique of Pure Reason. Nova York: Palgrave Macmillan, 2003

LEBRUN, G. Kant e o fim da metafísica. Trad. C. A. Ribeiro de Moura. São Paulo: Martins Fontes, 2002.

LEBRUN, G. A aporética da coisa em si. In LEBRUN, G. Sobre Kant. São Paulo: Iluminuras, 2001

LICHT, P. Algumas observações sobre a dialética transcendental: o fim da Crítica da razão pura. In Studia Kantiana, v. 6/7, 2008.

LOUZADO, G. O paradoxo das coisas em si mesmas. In O que nos faz pensar 19 (2005): 149-164. LONGUENESSE, B. Kant et le pouvoir de juger. Paris: Pr. Universitaires de France, 1993.

MATTOS, FC. Kant e o problema da coisa em si. Perspectiva de uma reflexão racional. In Cadernos de Filosofia Alemã 5, (1999): 27-44.

SANTOS, L.R. dos. Metáforas da razão... Lisboa: Fund. Calouste Gulbenkian, 1994.

SEEL, G. Die Einleitung in die Analytik der Grundsätze, der Schematismus und die obersten Grundsätze. In MOHR, G; WILLASCHEK, M (hrsg) Immanuel Kant, Kritik der reinen Vernunft. Berlin: Akademi Verlag. 1998. (pp. 217- 246).

SUZU KI, M. O gênio Romântico. São Paulo: Ed. Iluminuras, 1998.

ZÖLLER, G. Possibiliser l'expérience: Kant sur la relation entre le transcendantal et l'empirique. In GRANDJEAN (org) . Kant et les empirimes. Paris: Classiques Garnier, 2017 (pp. 99-112).

Autor(a) para correspondência / Corresponding author: Paulo Borges de Santana Júnior. pauloemconstrucao@gmail.com 